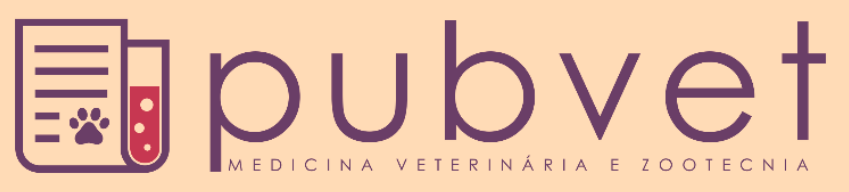

ISSN 1982-126

https://doi.org/10.31533/pubvet.v13n7a373.1-5

\title{
Infestação por Felicola subrostratus em felinos de gatil em Igarassu, Pernambuco, Brasil: relato de caso
}

\author{
Nicolli de Albuquerque Leal Gomes D'Alcantara ${ }^{*} \bullet$, Magda Maria de Abreu Silva ${ }^{1} \bullet$, Eryka \\ Crystyane Conceição do Nascimento Silva ${ }^{\bullet}$, Andreza de Cássia Gomes Araújo ${ }^{1}{ }^{\bullet}$, Liana \\ Mesquita Vilela $^{2}$, Ana Luiza Neves Guimaraes Bessa ${ }^{3} \bullet$ \\ ${ }^{I}$ Discentes do Centro Universitário Maurício de Nassau, Departamento de Medicina Veterinária. Recife - PE, Brasil. \\ ${ }^{2}$ Médica Veterinária, Docente do Centro Universitário Maurício de Nassau, Departamento de Medicina Veterinária, Recife-PE, Brasil. \\ ${ }^{3}$ Médica Veterinária do Hospital Municipal da Cidade do Recife - PE, Brasil. \\ *Autor para correspondência, E-mail: nicollileal@ hotmail.com
}

\begin{abstract}
Resumo. O Felicola subrostratus é um ectoparasita que causa pediculose especificamente em felinos e, apesar de ter distribuição mundial, sua ocorrência é incomum e pouco relatada. A pediculose pode se apresentar como uma das causas de prurido intenso em gatos, ocasionando dermatite, alopecia e infecções bacterianas secundárias, ou ainda, de forma assintomática, sendo os animais de pelos longos, os mais severamente afetados. $\mathrm{O}$ presente trabalho pretende relatar o primeiro caso diagnosticado de infestação por piolhos F. subrostratus em um Gatil com 14 felinos em Jardim Sumaré, na Vila Rural de Igarassu, em Pernambuco, onde 12 gatos apresentaram sintomatologia variada e dois desses animais foram examinados e tiveram amostras de pelos coletadas para exame parasitológico, sendo confirmada a infestação. Foi instituído tratamento com $1 \mathrm{ml}$ de Fipronil tópico para cada um dos 14 felinos contactantes e sete dias após aplicação do medicamento, os animais já apresentavam regressão do quadro clínico e ausência de ectoparasitas.
\end{abstract}

Palavras chave: ectoparasitas, malófagos, pediculose felina, piolhos

\section{Infestation by Felicola subrostratus in cat cats in Igarassu, Pernambuco, Brazil: case report}

\begin{abstract}
The Felicola subrostratus is an ectoparasite that causes pediculosis specifically in felines and, despite having a worldwide distribution, its occurrence is uncommon and poorly reported. Pediculosis may present as a cause of intense pruritus in cats, causing dermatitis, alopecia and secondary bacterial infections, or asymptomatically, and the animals with long hairs are most severely affected. The present work intends to report the first diagnosed case of $F$. subrostratus lice infestation in a Cat with 14 cats in Jardim Sumaré, in the Rural Village of Igarassu, in Pernambuco State, where 12 cats presented varied symptoms and two of these animals were examined and had samples of hairs collected for parasitological examination, confirming the infestation. Treatment with $1 \mathrm{ml}$ of topical Fipronil was instituted for each of the 14 contact cats and seven days after application of the drug, the animals already presented regression of the clinical picture and absence of ectoparasites.
\end{abstract}

Keywords: ectoparasites, malophages, feline pediculosis, lice 


\title{
Infestación por Felicola subrostratus en felinos de gatil en Igarassu, Pernambuco, Brasil: reporte de caso
}

\begin{abstract}
Resumen. El Felicola subrostratus es un ectoparásito que causa pediculosis específicamente en felinos y, a pesar de tener distribución mundial, su ocurrencia es inusual y poco relatada. La pediculosis puede presentarse como una de las causas de prurito intenso en gatos, ocasionando dermatitis, alopecia e infecciones bacterianas secundarias, o, de forma asintomática, siendo los animales de pelos largos, los más severamente afectados. El presente trabajo pretende relatar el primer caso diagnosticado de infestación por piojos $F$. subrostratus en un criadero con 14 felinos en Jardim Sumaré, en la Villa Rural de Igarassu, en Pernambuco, donde 12 gatos presentaron sintomatología variada y dos de esos animales fueron examinados y tuvieron muestras de pelo recogido para examen parasitológico, siendo confirmada la infestación. Se estableció tratamiento con $1 \mathrm{ml}$ de Fipronil tópico para cada uno de los 14 felinos contactantes y siete días después de la aplicación del medicamento, los animales ya presentaban regresión del cuadro clínico y ausencia de ectoparásitos.
\end{abstract}

Palabras clave: ectoparásitos, malófagos, pediculosis felina, piojos

\section{Introdução}

O prurido consiste no problema cutâneo mais comum em gatos, estando entre as três causas mais frequentes os parasitos, as infecções e as doenças alérgicas cutâneas. A infestação por piolhos, também chamada pediculose, pode ser considerada uma das causas parasitárias de prurido em felinos. Os piolhos são descritos como artrópodes da classe Insecta, ordem Phthiraptera, que podem ser contraídos através do contato direto com outro hospedeiro infectado (Nelson \& Couto, 2015). Os piolhos são considerados ectoparasitas de espécie-específica, com uma alta especificidade de hospedeiro o que facilita sua identificação (Pereira et al., 2017).

O Felicola subrostratus é descrito como o único piolho de felinos de interesse médico veterinário (Figueiredo et al., 2013; Pereira et al., 2017), é um piolho com aparelho bucal mastigador, classificado na subordem Mallophaga e família Trichodectidae (Rey, 1991; Urquhart, 1996) e, embora tenha distribuição mundial, sua infestação ainda é considerada incomum. Apesar de ser uma das causas de prurido intenso em felinos, ocasionando dermatite, perda de pelos e podendo ocasionar infecções bacterianas secundárias, sua infestação também pode ser assintomática, sendo os animais de pelos longos, os mais severamente afetados (Ahid, 2010).

Sendo a pediculose atípica em gatos e não sendo encontrado nenhum outro relato de infestação por este parasito nesta região, objetivou-se relatar o primeiro caso de infestação por $F$. subrostratus em Felinos de um Gatil em Jardim Sumaré, na Vila Rural de Igarassu, em Pernambuco e contribuir para o estudo epidemiológico desta parasitose no Brasil facilitando seu tratamento e sua identificação na população de gatos domésticos.

\section{Material e métodos}

Foi examinado em Recife-PE, um casal de gatos castrados, adultos, SRD, residentes em um Gatil em Jardim Sumaré, na Vila Rural de Igarassu, em Pernambuco. Foi relatado que os animais pertenciam a um grupo de 14 felinos, onde 12 (sete fêmeas e cinco machos) apresentaram sinais de alopecia e 10 deles, além da alopecia apresentaram prurido intenso. Na avaliação clínica dos animais foi possível observar a presença de ectoparasitas em deslocamento, principalmente em região de face, pescoço e próximo à cauda. Foi constatada a alopecia (Figura 1) e a presença de lesões e crostas (Figuras 2 e 3), consequentes do prurido intenso que os animais apresentavam. Foi retirada uma amostra de pelos para exame parasitológico, que foi submetido ao exame direto com microscopia óptica, onde foi identificada a infestação por Felicola subrostratus (Figura 4). Após confirmação do diagnóstico, foi iniciado o tratamento com $1 \mathrm{ml}$ de Fipronil a 1\%, "pour on", no dorso de todos os felinos que conviviam no mesmo ambiente e 7 dias após aplicação do medicamento, os animais já apresentavam regressão do quadro clínico e ausência de ectoparasitas. Foi realizada a limpeza de todos os utensílios utilizados por esses 
animais, bem como a pulverização do ambiente com Amitraz (Triatox ${ }^{\circledR}$ ) na diluição de $20 \mathrm{ml}$ para 10 litros de água. Antes da reaplicação da dose prescrita para 30 dias após o início do tratamento, os animais foram reavaliados, onde foi confirmada a cura clínica e o crescimento dos pelos.

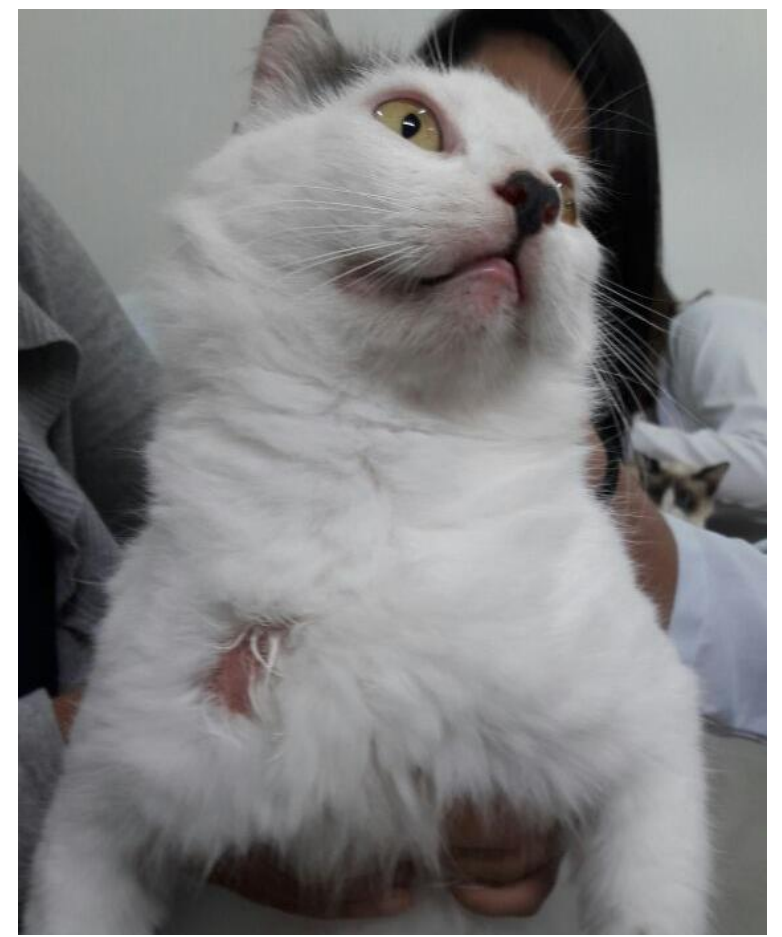

Figura 1. Área de alopecia em região peitoral

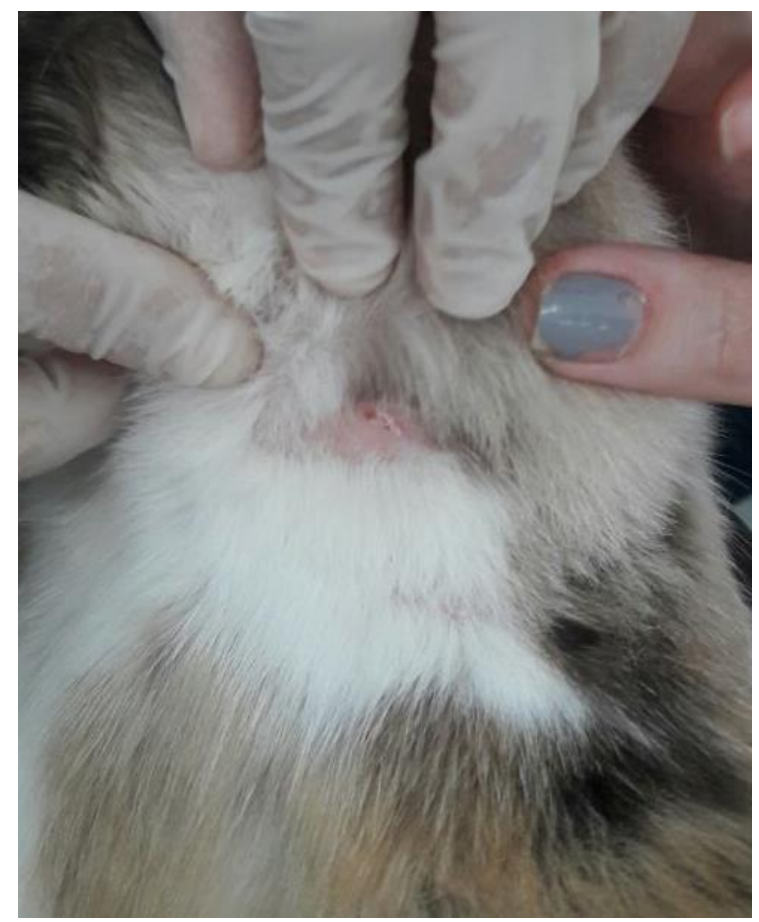

Figura 3. Lesão e área de alopecia em região de pescoço

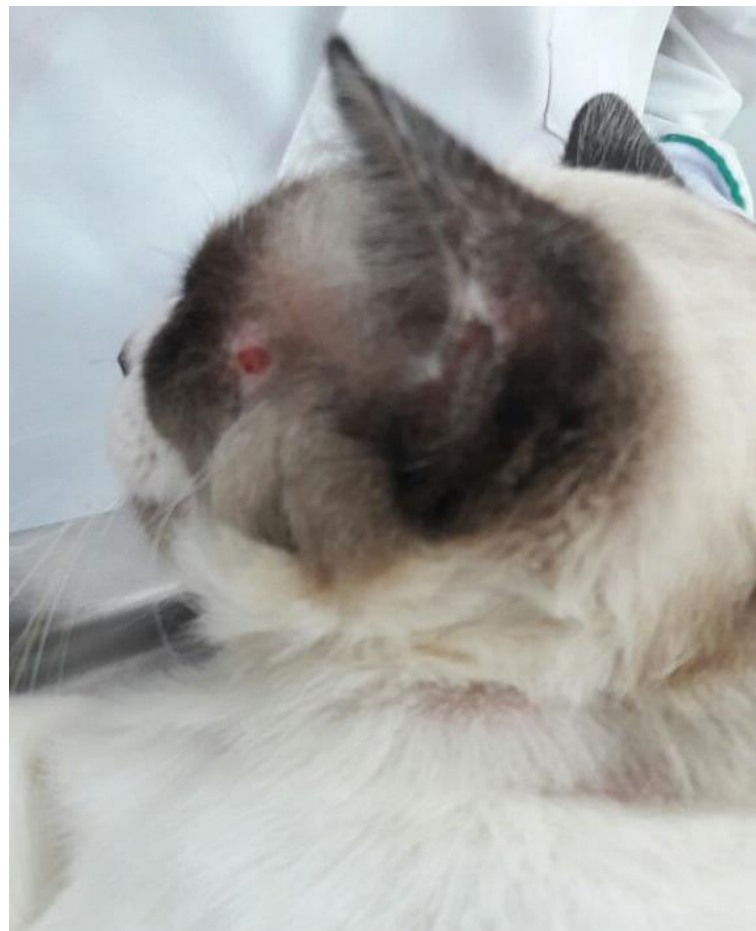

Figura 2. Crosta em região de face consequente do prurido intenso

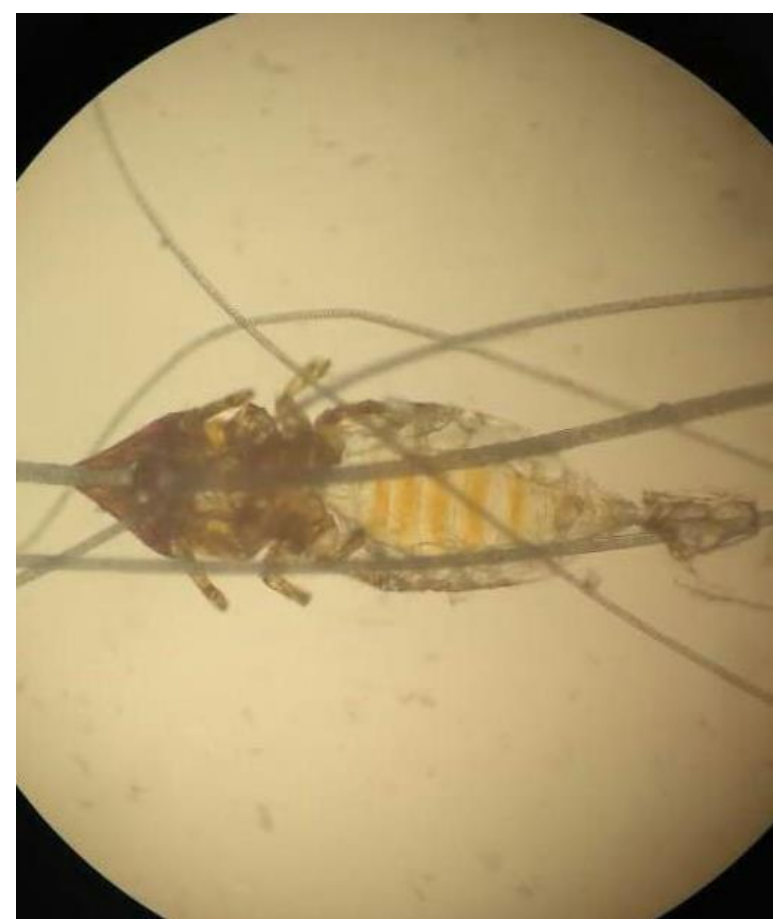

Figura 4. Piolho da espécie $F$. subrostratus visualizado em microscopia direta (100x)

\section{Resultados e discussão}

Os piolhos são ectoparasitas espécie-específicos contraídos por contato direto com outro hospedeiro infectado, sendo que os gatos são acometidos por apenas uma espécie de piolho, o Felicola subrostratus 
(Nelson \& Couto, 2015). Segundo Aguiar et al. (2009), embora tenha distribuição mundial, a infestação por F. subrostratus ocorre com pouca frequência na rotina médica veterinária, isso pode acontecer por não ser percebida pelos tutores quando em casos assintomáticos ou quando os animais apresentam sinais clínicos mais leves.

No presente relato, alguns felinos apresentaram prurido intenso, sinais de alopecia e presença de lesões. Outros apresentaram sinais mais brandos e dois deles não apresentaram nenhuma sintomatologia corroborando os dados relatados por Argus et al. (2016), que afirmam que a infestação por piolhos pode ser assintomática ou apresentar prurido variado. Ahid (2010) afirma ainda que animais mais sensíveis podem apresentar alopecia e prurido intenso, que terminam por ocasionar dermatites graves e a possibilidade de infecções secundárias.

Segundo Jericó et al. (2015) as infestações por piolhos podem ocorrer principalmente em locais com grandes concentrações de animais, nos quais não é feita a higienização correta, porém, apesar dos felinos viverem em um Gatil, com certa rotatividade de animais, o local apresentava boas condições higiênicosanitárias e controle de vetores. Pereira et al. (2017) afirmam ainda que as pediculoses acometem com maior frequência animais errantes, negligenciados e subnutridos, porém, neste caso os felinos apresentavam um bom estado físico, com peso ideal e estavam todos castrados, vacinados e vermifugados.

Todos os felinos que conviviam no mesmo ambiente foram tratados, mesmo os que não apresentaram sintomatologia. Segundo Hnilica \& Patterson (2011) todos os animais da mesma espécie que estiverem em contato direto devem ser tratados e o ambiente higienizado, não sendo necessário mais que uma desinfecção do local, já que os piolhos sobrevivem no máximo dois dias sem parasitar o hospedeiro. No período da infestação, além da limpeza habitual que é realizada no gatil com sabão em pó e água sanitária, foi feito o uso também de pulverização com Amitraz (Triatox ${ }^{\circledR}$ ) na diluição de $20 \mathrm{ml}$ do produto em 10 litros de água.

Segundo Nelson \& Couto (2015) esses parasitos geralmente têm ciclo de vida de 21 dias, sendo assim recomendado tratamento de quatro semanas. As opções de tratamento encontradas na literatura são variadas, em relato de Argus et al. (2016) foi utilizada em um grupo de 6 gatos a Selamectina 6\% $\left(\right.$ Revolution $\left.^{\circledR}\right)$, que debelou a infestação em poucos dias. Pereira et al. (2017) fizeram uso de Imidacloprida e moxidectina (Advocate ${ }^{\circledR}$ ) tópico e também obtiveram eliminação completa dos ectoparasitas em poucos dias. Neste caso, a escolha do protocolo com aplicação tópica mensal apenas de Fipronil 1\%, que é um pulicida que apresenta ação piolhicida, também se mostrou eficaz, uma vez que 7 dias após aplicação do medicamento, os animais já apresentavam regressão do quadro clínico e ausência de ectoparasitas e antes mesmo da reaplicação da dose, que havia sido prescrita para 30 dias após o início do tratamento, todos os animais foram reavaliados, sendo assim confirmada a cura clínica e o crescimento dos pelos (Figura 5).

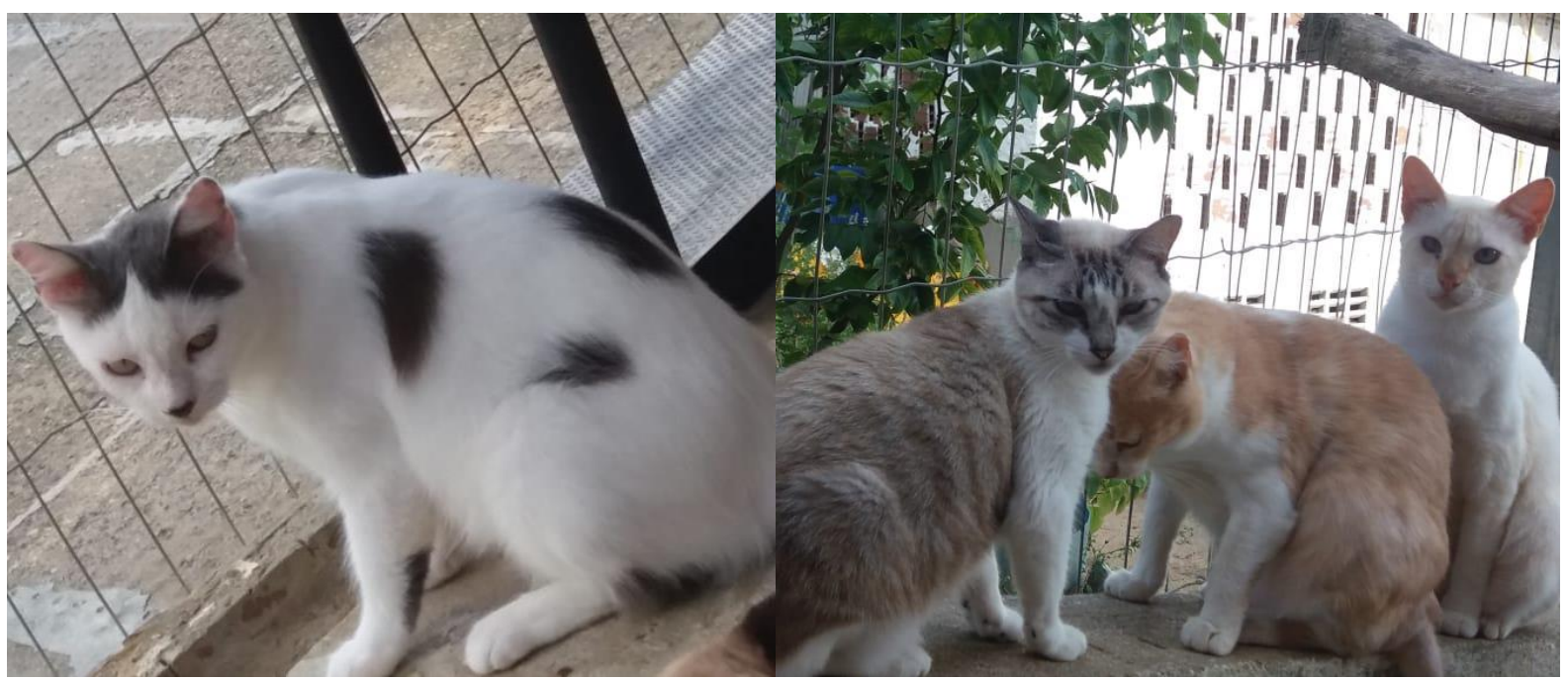

Figuras 5. Felinos apresentando crescimento dos pelos e regressão total do quadro clínico após tratamento 


\section{Conclusão}

Sendo a pediculose de ocorrência pouco comum em gatos e não sendo encontrado nenhum outro relato de infestação por este parasito nesta região, pretende-se chamar atenção para a possibilidade de infestação por $F$. subrostratus e para a importância de que esta seja considerada no diagnóstico diferencial de dermatopatias alopécicas e pruriginosas em felinos. É importante relatar que o seu tratamento é simples, desde que seja bem diagnosticado e que atinja o ambiente e os animais contactantes.

\section{Referências bibliográficas}

Aguiar, J., Silva, M. M. L., Rodrigues, F. R., Stieven, H. P., Cunha, M. A. \& Zazycky, R. R. (2009). Infestação mista por Lynxacarus radovskyi e Felicola subrostratus em um gato na região de Porto Alegre, RS, Brasil. Acta Scientiae Veterinariae, 37(3):301-305.

Ahid, S. M. M. (2010). Apostila Didática em Entomologia Veterinária. Mossoró, Rio Grande do Norte, Brasil: UFERSA.

Argus, A. P. V., Claus, M. P., Caovila, J. J., Camargo, K. S., Soares, M. E. B. \& Milczewski, V. (2016). Presença de Felicola subrostratus em Felis catus no Município de Joinville - SC. Paper presented at the I Semana de Ensino Pesquisa e Extensão - IFC Araquari, Florianópolis, Santa Catarina, Brasil.

Figueiredo, M. A. P., Manrique, W. G. \& Guerra, R. M. (2013). Felicola subrostratus parasitando gatos domésticos de São Luís, Maranhão, Brasil: relato de caso. Biotemas, 26(3):255-259.

Hnilica, K. A. \& Patterson, A. P. (2011). Small animal dermatology: a color atlas and therapeutic guide: Elsevier Health Sciences.

Jericó, M. M., Kogika, M. M. \& Andrade Neto, J. P. (2015). Tratado de medicina interna de cães e gatos. Rio de Janeiro, Brasil: Guanabara Koogan.

Nelson, R. W. \& Couto, C. G. (2015). Medicina interna de pequenos animais. Amsterdan: Elsevier Editora.

Pereira, N. B. A., Lee, L. T. \& Vieira, L. R. (2017). Infestação em Felis catus por Felicola subrostratus: Relato de Caso. PUBVET, 12(1):139.

Rey, L. P. E. G., Rio de Janeiro. (1991). Parasitologia. Rio de Janeiro, Brasil: Editora Guanabara. Urquhart, G. M. (1996). Parasitologia veterinária (2 ed.). Rio de Janeiro: Guanabara Koogan.

Recebido: 20 de maio, 2019.

Aprovado: 18 de junho, 2019

Publicado: 6 de agosto, 2019 .

Licenciamento: Este artigo é publicado na modalidade Acesso Aberto sob a licença Creative Commons Atribuição 4.0 (CC-BY 4.0), a qual permite uso irrestrito, distribuição, reprodução em qualquer meio, desde que o autor e a fonte sejam devidamente creditados. 